\title{
Functional Identification of a C-repeat Binding Factor Transcriptional Activator from Blueberry Associated with Cold Acclimation and Freezing Tolerance
}

\author{
James J. Polashock ${ }^{2}$ \\ U.S. Department of Agriculture, Agricultural Research Service, Genetic Improvement of Fruits \\ and Vegetables Laboratory, Blueberry and Cranberry Research Center, $125 \mathrm{~A}$ Lake Oswego Road, \\ Chatsworth, NJ 08019
}

Rajeev Arora and Yanhui Peng

Iowa State University, 139 Horticulture Hall, Ames, IA 50011-1100

Dhananjay Naik ${ }^{1}$ and Lisa J. Rowland

U.S. Department of Agriculture, Agricultural Research Service, Henry A. Wallace Beltsville

Agricultural Research Center, Genetic Improvement of Fruits and Vegetables Laboratory, Building 010A, 10300 Baltimore Avenue, Beltsville, MD 20705

\begin{abstract}
AdDitIONAL INDEX words. Vaccinium corymbosum, CBF/DREB, dehydration responsive, Arabidopsis thaliana
Aвstract. Highbush blueberry (Vaccinium corymbosum) is susceptible to winter freezing injury and frost damage in the spring. As part of an ongoing project to understand the process of cold acclimation, we isolated a C-repeat binding factor $(C B F)$ transcriptional activator gene-coding region from the highbush blueberry cultivar Bluecrop. Expression of the highbush blueberry $C B F$ gene was compared in floral buds of the cold-tolerant northern highbush cultivar Bluecrop and the more cold-sensitive southern rabbiteye ( $V$. virgatum) blueberry cultivar Tifblue. Relative gene expression was higher in 'Bluecrop' than in 'Tifblue'. Expression in both cultivars was highest at the earliest time point in the fall (coincident with the first stage of cold acclimation), declined during the later fall and winter, and, in 'Bluecrop', increased again as buds deacclimated, when temperatures tend to fluctuate. To confirm the putative identity of the gene as a member of the $C B F$ gene family, and to determine if expression in a heterologous system could enhance freezing tolerance, the blueberry gene coding sequence was overexpressed in transgenic Arabidopsis thaliana under the control of the cauliflower mosaic virus $35 \mathrm{~S}$ promoter. Transgenic plants expressing the putative blueberry $C B F$ gene exhibited induced expression of the $A$. thaliana cold-regulated $(C O R)$ genes $C O R 78$ and $C O R 6.6$, under noninducing conditions (i.e., $23^{\circ} \mathrm{C}$ ); however, expression of two other $C O R$ genes was unaffected. Transgenic plants also exhibited enhanced freezing tolerance under non-acclimated conditions, but not to the level of acclimated control plants. Thus, the expression pattern in floral buds and the ability of the isolated gene to turn on a subset of $C O R$ genes and increase freezing tolerance in a heterologous system suggest it is a functional member of the $C B F$ gene family in blueberry.
\end{abstract}

Enhanced cold tolerance, including tolerance to winter freezing and spring frosts, is needed for genetic improvement of current highbush blueberry cultivars (Moore, 1993). Freezing and cold injury not only cause direct crop loss through flower bud and shoot tip damage, but can cause indirect loss by predisposing the plants to pathogen infection such as stem blight caused by Botryosphaeria dothidea (Cline, 1995) and mummy berry caused by Monilinia vaccinii-corymbosi (Hildebrand and Braun, 1991). The response of plants to low temperatures is complex, requiring the activation of multiple genes and pathways (Fowler and Thomashow, 2002; Thomashow, 1999). The genes activated encode a diverse array of products, including enzymes required for the biosynthesis of osmopro-

Received for publication 1 Oct. 2009. Accepted for publication 12 Jan. 2010. We thank Kristia Adams for expert technical assistance and Jo Anne Crouch for assistance with the phylogenetic analysis.

${ }^{1}$ Current address: ITC R\&D Centre, Spark Tower, SP Biotech Park Pvt. Itd., Survey No's: 230-243, Shameerpet (Mandal)-500 078, A.P., India.

${ }^{2}$ Corresponding author. E-mail: james.polashock@ars.usda.gov. tectants and lipid desaturases, protective proteins such as dehydrins and chaperones, and antioxidants and proteins involved in signal transduction such as transcription factors and protein kinases (Fowler and Thomashow, 2002; Seki et al., 2001; Shinozaki and Yamaguchi-Shinozaki, 1996; Thomashow, 1999). Because one of the effects of freezing is cellular dehydration, many of the genes activated in response to cold temperatures are also induced under drought conditions (Stockinger et al., 1997; Wang et al., 1995). Expression of many genes in these overlapping pathways is induced by transcription factors called CBF (C-repeat or CRT binding factor). These transcription factors, best studied in Arabidopsis thali$a n a$, are induced quickly in response to cold and drought stress (Fowler and Thomashow, 2002; Gilmour et al., 1998; Liu et al., 1998; Shinwari et al., 1998; Stockinger et al., 1997).

In woody perennials such as blueberry (Vaccinium spp.), cold acclimation is considered a two-step process (Weiser, 1970). The first stage is thought to be induced by a short photoperiod, while the second stage, characterized by a more pronounced increase in freezing tolerance, is induced by low 
temperatures. In recent years, as part of our efforts to better understand the genetic basis of cold tolerance in blueberry, we have used approaches based on expressed sequence tags or ESTs (Dhanaraj et al., 2004), microarrays (Dhanaraj et al., 2007), and subtractive hybridization (Naik et al., 2007) to identify a variety of cold-responsive genes. We have focused primarily on genes expressed in floral buds during exposure to cold, as floral buds are susceptible to freeze/frost damage and, depending on the year, such damage can result in considerable yield losses. Transcription initiation factors such as CBF are desirable targets for further study because these activate the expression of a host of downstream genes that are associated with cold acclimation and freezing tolerance (Thomashow, 1999). Here, our objectives were to isolate a full-length CBF transcription factor from highbush blueberry, to compare expression of the putative $C B F$ gene in floral buds of coldtolerant and cold-sensitive blueberry cultivars throughout the dormant period from bud set to budbreak, to express the fulllength clone in transgenic $A$. thaliana to confirm its function as an inducer of $C O R$ (cold-regulated) gene expression, and to determine if expression of the putative blueberry $C B F$ gene enhances freezing tolerance in the transgenic $A$. thaliana.

\section{Materials and Methods}

ISOLATION AND SEQUENCING OF PUTATIVE $\boldsymbol{C B F}$ CLONES FROM HIGHBUSH BLUEBERRY. Previously, forward and reverse subtracted blueberry cDNA libraries were prepared that enriched for transcripts expressed at higher levels in dormant 'Bluecrop' flower buds at 400 and 0 chill units, respectively (Naik et al., 2007). The highbush blueberry cultivar Bluecrop was chosen because it is quite cold hardy and is the industry standard of highbush cultivars. One chill unit, as defined here, equals $1 \mathrm{~h}$ of exposure to temperatures between 0 and $7{ }^{\circ} \mathrm{C}$. The 0 and 400 chill unit time points corresponded to collection times on 29 Sept. 2003 and 8 Dec. 2003, respectively, and cold hardiness levels, expressed as lethal temperature ${ }_{50}\left(\mathrm{LT}_{50}\right)$ or temperature that kills $50 \%$ of the floral buds in a controlled freeze-thaw test, of -10 and $-25^{\circ} \mathrm{C}$, respectively (Muthalif and Rowland, 1994; Naik et al., 2007).

Random clones were picked and sequenced from both libraries, and a search of the National Center for Biotechnology Information (NCBI) non-redundant protein database using BLASTX (Altschul et al., 1990) revealed that four of 167 $(2.4 \%)$ randomly picked clones from the reverse subtracted library had significant homology to $\mathrm{CBF}$ gene products or the similar dehydration-responsive element binding (DREB) protein elements. Upon alignment of the four clones with $C B F$ gene homologs from other plants, it appeared that one clone, RL82 (GenBank accession no. DW043077), represented the 5' half of the gene, while the three other clones, RL6 (GenBank accession no. DW043065), RL44 (GenBank accession no. DW043054), and RL138 (GenBank accession no. DW043014), represented the $3^{\prime}$ half of the gene. Therefore, a forward primer (5' GCGCGAGTCTCCCACTATTA) was designed near the 5' end of the RL82 sequence and a reverse primer ( $5^{\prime}$ CAAGTTC TCTCTGTTTATAT) was designed near the $3^{\prime}$ end of the RL6 sequence using the Primer3 program (Rozen and Skaletsky, 2000). These primers were used in PCR reactions with 'Bluecrop' genomic DNA as template in an attempt to amplify one fragment that would span the entire translated portion of the putative blueberry $C B F$-coding region (hereafter referred to as
BB- $C B F$ ) plus about 150 bp on the $5^{\prime}$ and $3^{\prime}$ ends of the untranslated region (UTR). 'Bluecrop' genomic DNA isolation and polymerase chain reactions (PCR) were as previously described for the development of EST-PCR markers in blueberry (Rowland et al., 2003).

Using this approach, a fragment of the expected size $(\approx 1 \mathrm{~kb})$ was amplified and purified from a $1.4 \%$ agarose gel using the Ultraclean Gelspin Kit (MO BIO Laboratories, Solana Beach, $\mathrm{CA}$ ) according to the manufacturer's instructions. The purified fragment was cloned using the pGEM-T Vector System (Promega, Madison, WI) according to the directions provided. Recombinant plasmids were isolated using the Ultraclean Miniprep Kit (MO BIO Laboratories). Several isolates of the cloned fragment were cycle-sequenced using Cy5-labeled M13 forward and reverse primers and the SequiTherm EXCEL II Long-Read ${ }^{\mathrm{TM}}$ Kit (Epicentre Technologies, Madison, WI). Labeled primers were purchased from Integrated DNA Technologies, Inc. (Coralville, IA). Sequencing reactions were separated and detected on an ALF Express Sequencer (Amersham Pharmacia Biotech, Piscataway, NJ). Sequences were assembled using various modules of the Lasergene software package (DNASTAR, Madison, WI).

The identity of the putative BB- $C B F$ clone was confirmed by comparison with sequences posted in GenBank using nucleotide BLAST (Altschul et al., 1990). To further confirm the identity of the gene product, the translated sequence was compared with the non-redundant NCBI protein database using blastp (protein-protein Blast). Several similar sequences were downloaded for comparison. Alignment of the predicted amino acid sequences was performed using the M-Coffee web server (Moretti et al., 2007). Gaps were manually removed from the alignment and reintroduced into the dataset as coded characters. A midpoint-rooted phylogenetic tree was constructed in PAUP* (Swofford, 2000) using maximum parsimony performed with TBR branch swapping and a branch-and-bound search strategy. Bootstrap values supporting the branches were calculated using 1000 replicates.

The deduced amino acid sequence of the BB-CBF was aligned with several other CBF/DREB proteins published in GenBank using ClustalW. Graphic display was generated using the Geneious Pro software package (version 4.6.5; Biomatters, Auckland, New Zealand). Amino acid numbering is relative to a deduced consensus sequence.

EXPRESSION ANALYSIS OF THE BB-CBF GENE IN FLORAL BUDS OF THE NORTHERN HIGHBUSH BLUEBERRY CULTIVAR BLUECROP AND THE SOUTHERN RABBITEYE BLUEBERRY CULTIVAR TIFBLUE. TO study the expression pattern of the BB- $C B F$ gene in floral buds from bud set to budbreak, a time course experiment was performed using field-grown plants (Beltsville, MD) of the relatively cold-hardy highbush cultivar Bluecrop and the relatively cold-sensitive rabbiteye cultivar Tifblue. RNA was extracted from floral buds of 'Bluecrop' and 'Tifblue' field plants that had accumulated 0 (collected 29 Sept. 2003), 67 (20 Oct. 2003), 399 (8 Dec. 2003), 779 (2 Feb. 2004), and 1234 (13 Mar. 2004) chill units (defined as hours of exposure to temperatures between 0 and $7^{\circ} \mathrm{C}$ ). RNA was extracted from $\approx 600-\mathrm{mg}$ frozen samples using the hot borate protocol described by Wilkins and Smart (Wilkins and Smart, 1996). To remove any genomic DNA contamination, total RNA was treated with RNase-free DNase I (Promega). Total RNA ( $5 \mu \mathrm{g} /$ lane) from each time point was separated on $1 \%$ agarose/formaldehyde gels, visualized, and photographed to confirm quality and concentration. 
cDNA was synthesized from RNA using the SuperScript III First-Strand Synthesis SuperMix for qRT-PCR (Invitrogen, Carlsbad, CA) according to the manufacturer's protocol. The Power SYBR Green PCR Master Mix (Applied Biosystems, Foster City, CA) was used for the qPCR reactions. Primers for qPCR were designed using Primer Express 3.0 software (Applied Biosystems) and are listed in Table 1. Reactions were run on an Applied Biosystems 7500 real-time PCR machine. Assays were normalized using expression of a blueberry metallothionein gene, which does not change with cold acclimation based on previous northern blot (Dhanaraj et al., 2004) and microarray data (Dhanaraj et al., 2007). There were three replicates of each cultivar at each time point and each experiment was repeated twice with similar results. Relative expression levels were calculated by the $\Delta \Delta \mathrm{CT}$ method using the Applied Biosystems 7500 software package (version 2.0.1).

VECTOR CONSTRUCTION AND $\boldsymbol{A}$. THALIANA TRANSFORMATION. The sequenced isolates of the putative BB-CBF gene from blueberry were found to contain an EcoRI recognition site near the 3' end (nt 954-955). To facilitate downstream cloning, this site was removed by digestion with EcoRI, filling in the overhang, and ligating the blunt ends, using standard techniques (Sambrook et al., 1989). This construct was amplified in $E$. coli strain $\mathrm{DH} 5 \alpha$, and an isolate with the proper size insert, confirmed to lack the EcoRI site, was selected at random for plant transformation vector construction. This isolate was digested with SphI and PstI [these sites are in the pGEM-T vector (Promega Corporation) multiple cloning region] and the BB- $C B F$ fragment was gel purified and ligated into the pFF19 vector (Timmermans et al., 1990) digested with the same enzymes. The resulting plasmid was digested with HindIII and EcoRI, yielding the BB-CBF fragment downstream of the cauliflower mosaic virus $35 \mathrm{~S}$ promoter and enhancer and ended by the $35 \mathrm{~S}$ polyA signal. This fragment was gel purified and ligated into the Agrobacterium tumefaciens binary vector pCAMBIA 2301 (GenBank accession no. AF234316) digested with the same enzymes (HindIII and EcoRI). The completed

Table 1. Plant sources, target gene designations, GenBank accession numbers, and primer sequences used for real-time PCR assays.

\begin{tabular}{|c|c|c|}
\hline $\begin{array}{l}\text { Plant source and gene } \\
\text { designation }^{z}\end{array}$ & Accession no. & Primer sequences ${ }^{\mathrm{y}}$ \\
\hline Vaccinium corymbosum & & F-TCGGACGAGGAGCTGATGA \\
\hline Blueberry $C B F$ & FJ222601 & R-TCCCGGCTCGCTTCTTC \\
\hline V. corymbosum & & F-ACCCTGACATGAGCTTCTCG \\
\hline Blueberry metallothionein & CF811253 & R-ACCCAAATCTCTGCTTGCTG \\
\hline Arabidopsis thaliana & & F-TGATGGTCAACGGAAGGTCAA \\
\hline COR78 & NM_124610 & R-ACAGCCGACTCTTCCTCCAA \\
\hline A. thaliana & & F-CCAGGTGAACTTGAGCTTCCA \\
\hline COR414-TM1 & NM_102679 & R-TGATATGGCGCCACAATCA \\
\hline A. thaliana & & F-GGATGCCGACTTTGTTGGAT \\
\hline$C B F-1$ & NM_118681 & R-AGACGGCGGCGGTAAAA \\
\hline A. thaliana & & F-GGCCGCTGGCAAAGCT \\
\hline COR6.6 & X55053 & R-GCAGCATCCTTGGCCTTGT \\
\hline A. thatiana & & F-CGTTGATCTACGCCGCTAAAG \\
\hline COR $15 a$ & AY057640 & R-TGGCCTCGTTGAGGTCATC \\
\hline A. thaliana & & F-CGTGAGGATCAGCGCATTC \\
\hline EIF $4 A-2$ & NM_104305 & R-ACACGACCGGGAGTTCCA \\
\hline
\end{tabular}

${ }^{\mathrm{z}}$ Plant source (species) and target gene designations.

${ }^{y}$ All primer sequences are given $5^{\prime}$ to $3^{\prime}$. Forward and reverse primers are abbreviated $\mathrm{F}$ and $\mathrm{R}$, respectively. vector was transformed into A. tumefaciens strain GV3101 (pMP90) (Koncz and Shell, 1986) using the freeze-thaw method (An et al., 1988). A. thaliana plants (Columbia ecotype) were transformed using the floral dip method (Clough and Bent, 1998). The potentially transformed seeds were vapor-phase sterilized and selected on kanamycin-containing $\left(50 \mathrm{mg} \cdot \mathrm{L}^{-1}\right)$ half-strength Murashige and Skoog medium (Murashige and Skoog, 1962) supplemented with $2 \%$ sucrose and were solidified with $5 \mathrm{~g} \cdot \mathrm{L}^{-1}$ Agargel (Sigma-Aldrich, St. Louis).

EXPRESSION ANALYSIS OF ENDOGENOUS $A$. THALIANA $C B F 1$ AND $C O R$ GENES AND THE BB- $C B F$ TRANSGENE IN TRANSFORMED $\boldsymbol{A}$. THALIANA. Transformed $A$. thaliana seedlings (i.e., kanamycin resistant) were transferred to potting mix and grown in an environmental growth chamber (Conviron; Controlled Environments, Winnipeg, $\mathrm{MB}$, Canada) at $23{ }^{\circ} \mathrm{C}$ under $16 \mathrm{~h}$ of light provided by a high-pressure sodium lamp $\left(375 \mu \mathrm{mol} \cdot \mathrm{m}^{-2} \cdot \mathrm{s}^{-1}\right)$. The transgenic plants used were the S3 (third generation selfpollinated) plants that were transformed with the BB- $C B F$ gene modified for constitutive expression as described above. Two different lines were used [S3-7, nine plants (replicates) and S3-11, eight plants (replicates)] for all experiments. Eight untransformed plants were used as controls. RNA was isolated from leaf tissue from non-cold-treated $A$. thaliana plants immediately after removing them from the $23{ }^{\circ} \mathrm{C}$ growth chamber. The same plants were then moved to $4{ }^{\circ} \mathrm{C}$ overnight (12 h) and the RNA was isolated from the leaves for the coldtreated samples. RNA for all real-time PCR assays was isolated using the RNeasy Plant Mini Kit (Qiagen, Valencia, CA) according to the manufacturer's protocol. cDNA was synthesized using the SuperScript III First-Strand Synthesis SuperMix for qRT-PCR (Invitrogen) according to the manufacturer's protocol. The Power SYBR Green PCR Master Mix (Applied Biosystems) was used for the qPCR reactions. All of the primers used for qPCR were designed using the Primer Express 3.0 software (Applied Biosystems). Sequences for primer design were downloaded from GenBank, with the exception of the BB-CBF, which was based on our own sequence. All reactions were run on an Applied Biosystems 7500 real-time PCR machine. Assays were normalized using expression of eukaryotic translation initiation factor 4A-2 (eIF4A-2) (Gilmour et al., 2000; Metz et al., 1992). There were three technical replications in each run. Primers used are listed in Table 1.

COLD ACCLIMATION AND FREEZING TOLERANCE IN WILD-TYPE (WT) AND TRANSGENIC (OVEREXPRESSED BBCBF) A. thaliana Plants. For cold acclimation treatment, 3-week-old seedlings from the same lines used above (S3-7 and S3-11) were transferred from the growth chamber to a cold room at $3 \pm 1{ }^{\circ} \mathrm{C}$ and 50 $\mu \mathrm{mol} \cdot \mathrm{m}^{-2} \cdot \mathrm{s}^{-1}$ light intensity for $6 \mathrm{~d}$. Freezing tolerance (FT) tests were performed by subjecting plants to a controlled freeze-thaw regime (in a glycol bath) followed by the assessment of injury (and FT as $\mathrm{LT}_{50}$ ) by measuring electrolyte leakage 
from freeze-thaw-injured tissues as described (Jaglo-Ottosen et al., 1998; Peng et al., 2007). Three replicates (individual plants) per treatment temperature were used in FT tests, which were repeated three times. Freezing injury (and $\mathrm{LT}_{50}$ ) data presented are the mean of three independent experiments. Basically, non-acclimated (NA) and cold-acclimated (CA) WT and transgenic BB-CBF plants were placed in test tubes in a glycol bath for $1.5 \mathrm{~h}$ at $-1{ }^{\circ} \mathrm{C}$ in a completely randomized design, after which ice chips were added to initiate icenucleation. After an additional hour of incubation at $-1{ }^{\circ} \mathrm{C}$, the temperature was lowered at a rate of $1{ }^{\circ} \mathrm{C} / \mathrm{h}$ until it reached $-8{ }^{\circ} \mathrm{C}$ (for NA plants) or $-12{ }^{\circ} \mathrm{C}$ (for CA plants). Frozen samples at each treatment temperature were removed from the glycol bath and thawed on ice overnight followed by incubation in $20 \mathrm{~mL}$ of distilled water, vacuum infiltration (three times for 3 min each at $172.4 \mathrm{kPa}$ ), and shaking for $1 \mathrm{~h}$ at $250 \mathrm{rpm}$. Initial electrical conductivity (EC) was measured for each sample with a conductivity meter. Total conductivity for the same sample was determined after autoclaving at $121^{\circ} \mathrm{C}$ for $20 \mathrm{~min}$. Initial leakage was expressed as the percentage of the final conductivity, and the percentage of leakage for each treatment temperature was converted to percentage of injury (Lim et al., 1998). The temperature at which 50\% injury occurred $\left(\mathrm{LT}_{50}\right)$ was defined as the FT.

\section{Results}

Confirmation of the BB- $\boldsymbol{C B F}$ Sequence as a $\boldsymbol{C B F}$ gene. A putative $C B F$ gene fragment (about $1 \mathrm{~kb}$ ) was amplified from 'Bluecrop' highbush blueberry genomic DNA using PCR primers based on EST clones of what appeared to be the $5^{\prime}$ and $3^{\prime}$ ends of a $C B F$-like gene. The fragment was purified, cloned, and sequenced. The putative highbush BB- $C B F$ nucleotide sequence (GenBank accession no. FJ222601) was compared with other sequences in the GenBank database and had a high similarity (e-values $<10^{-26}$ ) to numerous $C B F / D R E B$ sequences, with the greatest identity associated with the conserved AP2 binding domain-coding region (data not shown). To further confirm the identity of the gene, the translated sequence was compared with the non-redundant NCBI protein database, and several similar sequences were downloaded for comparison. The phenogram resulting from a PAUP* analysis (Fig. 1) supports the identity of the blueberry sequence as a $C B F / D R E B$ gene and shows that similarity is highest to the Vaccinium vitis-idea (lingonberry) DREB1 deduced amino acid sequence (accession no. ACJ54953). Of the sequences downloaded for comparison, the BB-CBF was least similar to the $A$. thaliana $\mathrm{CRT} / \mathrm{DRE}$ binding factor 2 (used as the out-group in the phenogram).

The BB-CBF protein has a predicted molecular weight of $24.7 \mathrm{kDa}$ and an isoelectric point of $\approx 7$. The deduced amino acid sequence of the BB-CBF protein was found to contain the ERF/AP2 DNA-binding domain (Fig. 2). The CBF signatures (Jaglo et al., 2001) ETRHP/DSAWR are also present, but the DSAWR signature has been modified from DSAWR to DSVWR in the blueberry protein. This amino acid substitution (A to $\mathrm{V}$ ) is also present in the $V$. vitis-idea DREB1. Phylogenetic analysis of the downloaded CBF/DREB proteins generally shows groupings by accepted taxonomic relationships rather than specific gene function.

EXPRESSION OF THE BB-CBF GENE IN FLORAL BUDS OF COLDTOLERANT AND COLD-SENSITIVE BLUEBERRY CULTIVARS. The

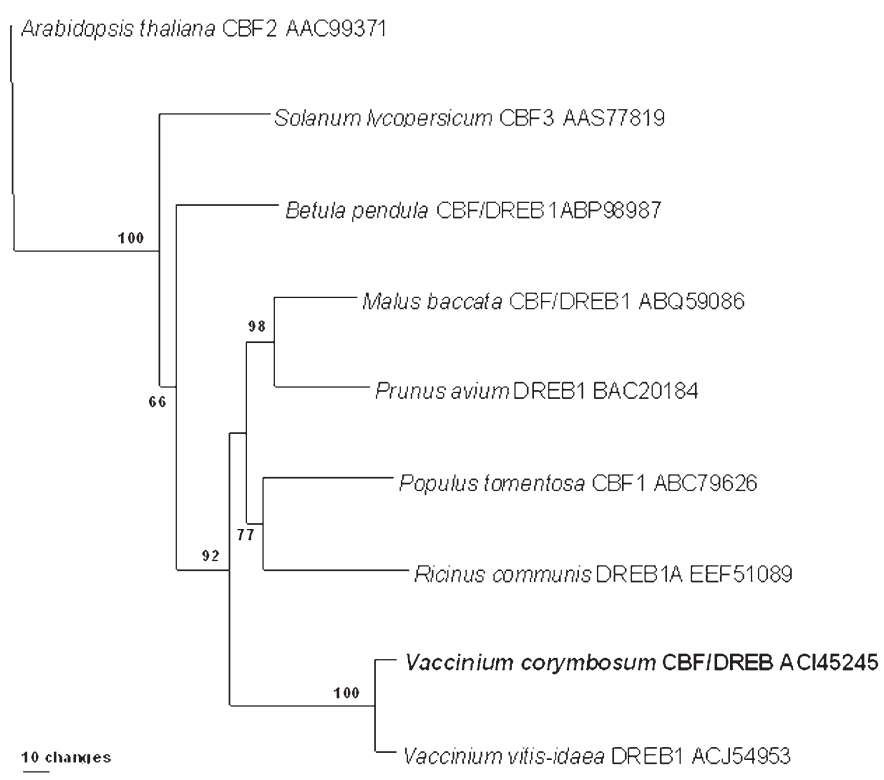

Fig. 1. Phylogenetic tree showing similarity of the highbush blueberry (Vaccinium corymbosum) C-repeat binding factor $(C B F)$ gene deduced amino acid sequence to those described from other species. Species names are followed by the gene designation as posted in GenBank and the corresponding accession numbers. The tree was rooted using Arabidopsis thaliana C-repeat (CRT) dehydration responsive element (DRE) binding factor 2 (CBF2). Bootstrap values higher than 50 are shown above or below branch points as space permitted.

expression pattern of the BB- $C B F$ gene was compared in floral buds of field-grown plants of the relatively cold-hardy highbush cultivar Bluecrop and the relatively cold-sensitive rabbiteye cultivar Tifblue using real-time PCR (Fig. 3). A time-course experiment was performed to monitor expression from bud set to budbreak (about the end of September through the middle of March). 'Bluecrop' flower buds generally reach a maximum midwinter cold hardiness level of about of $-27{ }^{\circ} \mathrm{C}$, whereas 'Tifblue' is generally cold hardy to about $-20{ }^{\circ} \mathrm{C}$ (Arora et al., 2004; Dhanaraj et al., 2007; Rowland et al., 2005). Expression of BB- $C B F$ was found to be higher in the cold-hardy 'Bluecrop' than in the cold-sensitive 'Tifblue'. Additionally, in both cultivars, expression was highest at the earliest time point in the fall, at the first stage of cold acclimation, and declined during the later fall and winter. In 'Bluecrop', expression increased slightly by the last time point as buds were deacclimating, when temperatures tend to fluctuate. The largest difference in CBF-mRNA levels between the two cultivars was at the first time point, in late September, when CBF-mRNA levels were almost 4-fold higher in 'Bluecrop' than in 'Tifblue'.

COR GENE ACTIVATION IN TRANSGENiC $A$. THALIANA. To determine if the BB-CBF gene product could activate coldregulated $(C O R)$ genes known to be part of the $C B F$ regulon, the relative expression levels of several $C O R$ genes were monitored using real-time PCR in transgenic (expressing the BB- $C B F$ gene) and WT $A$. thaliana under normal (noninducing temperature) and cold-treated conditions (Fig. 4). The two lines of transgenic plants (S3-7 and S3-11) always exhibited similar expression levels of the genes tested under the same treatments (i.e., the same expression levels when cold treated and also the same expression levels under non-inducing conditions). Therefore, the data from both lines were combined to generate the graph (Fig. 4). The relative expression levels of 


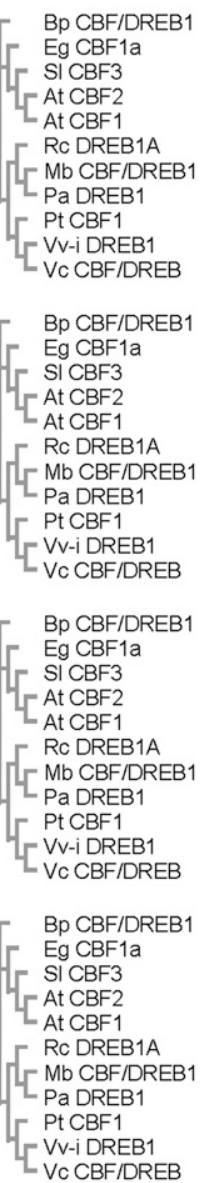
KRAGRKKFRETRHPVYRGVRLRDSGKWWCEVREPI -KKSRI WM GTFPTVEMAARAHDVAALALRGRS--ACL KPAGRKKFRETRHPVYRGVRKRNSGKWWCEVREPN-KKTRI WI GTFPTAEMAARAHDVAAI ALRGRS--ACL KPAGRKKFRETRHPI YRGVRQRNSGKWWCELREPN-KKTRI WL GTFQTAEMAARAHDVAAI ALRGRS--ACL KPAGRKKFRETRHPI YRGVRQRN SGKWWSEVREPN -KKTRI ML GTFQTAEMAARAHDVAALALRGRS--ACL KPAGRRVFKETRHPVFRGVRRRNGNKWWCEVRVPN -KKSRI WL GTYPTPEMAARAHDVAALALRGKS - -ACL KRAGRRVFNETRHPVYRGVRRRNNDKWWCEMREPNKKKSRI WM GAYPTAEMAARAHDVAALAFRGRL - -ACL KRAGRRVFKETRHPVYRGVRRRNNDKWWCEMREPNKKKSRI WL GTYPTAEMAARAHDVAALAFRGKL --ACI KRAGRRI FKETRHPI FRGVRKRNGDKWWCELREPN-KKSRI WL GTYPTPEMAARAHDVAALAFRGKS - -ACL KRAGRKKF KETRHPI YRGVRRRNNDRWWCELREPN-KKSRL W GTYPTAEMAARAHDVAALAL KGESPTACL KRAGRKKF KETRHP I YRGVRRRNN GRWWCELREPN -KKSRL WL GTYPTAEMAARAHDVAALAL KSESS KACL

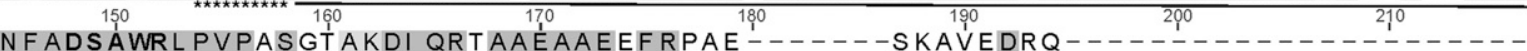
NFADSAWRLPVPASGTAKDI QRTAAEAAEEFRPAE - - NFADSAWRLPTPDSSDT KDI QKAAAQAAEI FRPL K - -SEEEESVVKDQST - - - - - - - - - - - - - - - - NFADSAWRLRI PESTCAKEI QKAAAEAALNFQDEM--CHMT TDAHGLDMEETL VEAI - - - - - YTPE-- - NFADSAWRLRI PEST CAKDI QKAAAKAALAFQDET - -CDT T T T DHGLDMEETMVEAI - - - - -YTPE-- - NFSDSAWRLPI PSST SAREI RRI AAEAAESFRPQEFGCPGEQN SSTEDHPSGACCDE - - - - - - - - - - NFADSAWRL PVPASTDSVDI RRAAAEAAETFRPAE - -FGGVSE S GDDEKE SKKME GEKDCGCAEQSDCGRAE NFADSAWRL PVPASMDT MDI RRAAAEAAE GFRPVE - -FGGVCS GSSDEKERMVVQVE - - - - - EKNKKGSVN NFADSAWRLPAPI SNEAKDI RRAASEAAELFRTSD--LGGQVMEDHTTENRGEVCSS--- - - TNDDI RDL -

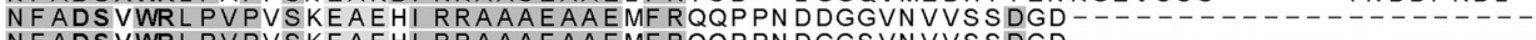
NFADS VWRL PVPVSKEAEHI RRAAAEAAEMF RQQPPN DGGSVN VVSSDGD - - - - - - - - - - - - -

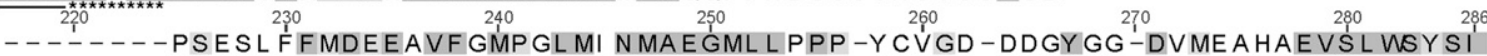

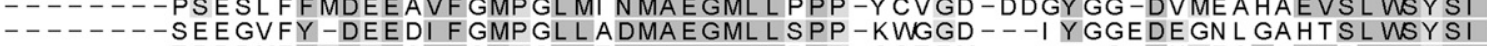

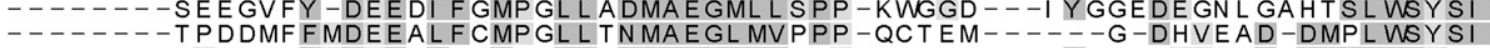
- - - - - - QSE GAFYMDEE TMF GMP SLL DN MA GML LPPP - - - - - - SVQWN HNY DGE GDGDVSLWSY - - - - - -SKT TVPFMDAEEVFDMPSLL VEMAQGL LL SPL -RFEEDVGT DW- - -NGLENDFDI SL WSD QSDCGGAEQSGSSFYLDEEEMFAMPRLLDSMAEGLLLSPPRRSAGS -N MNWD - -DMGSNDDDVNLWSFSK LERS - - - RSL SL SYWDEEEVF HMPRLL HDMAE GL LL SPS -QCL GG--- YMN L DDMGTDADVKL WSF SI

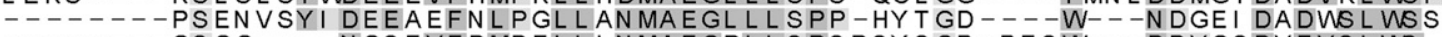
- - - - - GSGG----NGSEVFDMDELI LNMAEGPLLSPSPSYSGR-RF SW- - DDVGSDVEVSLWS -..-.--GSGG-.--NGSEVFDMDEL LLNMAEGPLLSPSPSYSGR-RF SW- - -DDVGSDVEVSLWS

Fig. 2. Multiple alignment of the amino acid sequences of C-repeat binding factor/dehydration responsive element binding factor (CBF/DREB) proteins. Alignment numbers are relative to a deduced consensus sequence. Shaded regions show high similarity $(60 \%-100 \%)$, based on the Blosum62 matrix. Unshaded regions are less than $60 \%$ identical. The ethylene-responsive element binding factor/APETELA2 (ERF/AP2) DNA-binding domain is underlined and the CBF signatures [ETRH and DS(A/V)WR] are indicated by **** and are in bold. A neighbor-joining tree based on the alignment is shown in the left margin. Abbreviations (species followed by the GenBank accession numbers) are as follows: Bp CBF/DREB1 = Betula pendula ABP98987, Eg CBF1a = Eucalyptus gunnii DQ241820, Sl CBF3 = Solanum lycopersicum AAS77819, At CBF1 = Arabidopsis thaliana AY667247, At CBF2 = Arabidopsis thaliana AAC99371, Rc DREB1A = Ricinus communis EEF51089, Mb CBF/DREB1 = Malus baccata ABQ59086, Pa DREB1 = Prunus avium BAC20184, Pt CBF1 = Populus tomentosa ABC79626, Vv- $\mathrm{i}$ DREB1 = Vaccinium vitis-idea $\mathrm{ACJ} 54953$, and Vc CBF/DREB = Vaccinium corymbosum ACI45245.

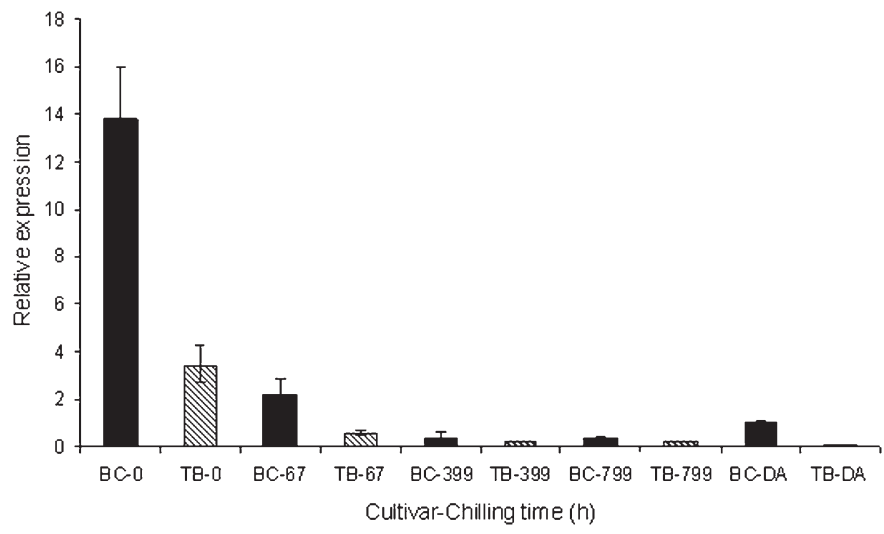

Fig. 3. Relative expression of the highbush blueberry C-repeat binding factor $(\mathrm{BB}-C B F)$ gene in the cold-hardy northern highbush blueberry cultivar Bluecrop (BC) and the less cold-hardy rabbiteye blueberry cultivar Tifblue (TB) at various stages of chilling-hours accumulation $(0,67,399$, and 799 chilling hours), which is defined as hours of exposure to temperatures between 0 and $7^{\circ} \mathrm{C}$. Error bars are $95 \%$ confidence intervals. DA $=$ deacclimating and corresponds to exposure to about 1234 chilling hours.

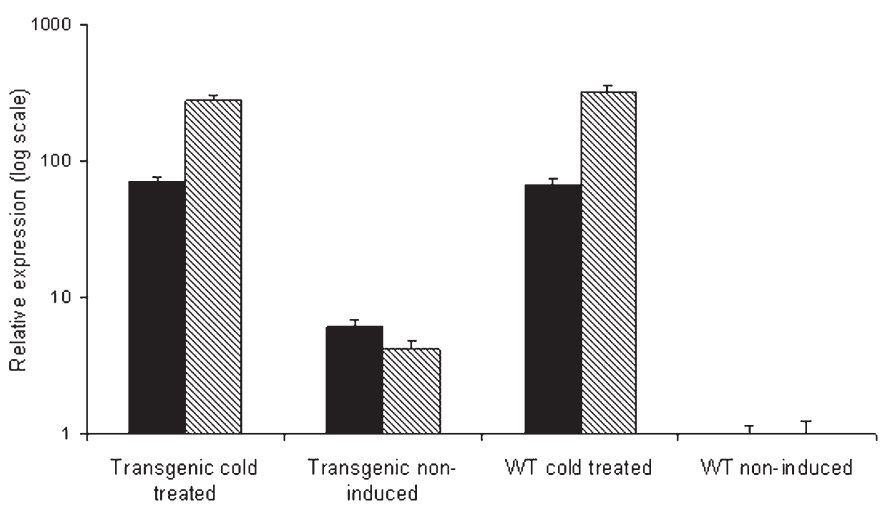

Fig. 4. Relative expression of cold-responsive (COR) genes COR6.6 (solid bars) and $C O R 78$ (hatched bars) in the highbush blueberry C-repeat binding factor (BB- $C B F$ ) overexpressing (Transgenic) and untransformed (WT) Arabidopsis thaliana under cold-treated (exposed to $4{ }^{\circ} \mathrm{C}$ for $12 \mathrm{~h}$ ) and non-induced (maintained at $23{ }^{\circ} \mathrm{C}$ ) conditions. Error bars are $95 \%$ confidence intervals. 
the endogenous $A$. thaliana $C B F 1$ and the BB-CBF transgene were also monitored to confirm expression of the transgene in the appropriate plants and to determine if expression of the blueberry transgene affected expression of the endogenous $A$. thaliana $C B F 1$ gene. The results indicated that the blueberry transgene was very highly expressed in the transgenic $A$. thaliana under all conditions (data not shown). Following cold treatment, all tested COR genes (COR78, COR6.6, COR15A, and COR414-TM1) were highly expressed in WT and transgenic plants. The endogenous $A$. thaliana $C B F 1$ gene was also expressed at similar levels in the WT and transgenic plants (data not shown). Under non-inducing conditions, COR78 and COR6.6 were upregulated in the transgenic plants, presumably due to activation by the BB-CBF gene product. The other $C O R$ genes tested (COR15A and COR414-TM1) were not activated under non-inducing conditions in all plants tested (data not shown). Transgenic plants overexpressing the BB-CBF gene appeared phenotypically normal (i.e., the same as WT) under all conditions tested (Fig. 5, A and B).

Freezing tolerance of transgenic $\boldsymbol{A}$. thaliana. The FT $\left(\mathrm{LT}_{50}\right)$ of NA WT and transgenic (BB-CBF) S3-7 and S3-11 seedlings were about $-3.99,-4.73$, and $-4.84{ }^{\circ} \mathrm{C}$, respectively (Fig. 6A, Table 2). Moreover, the relative level of freeze-thaw injury of WT plants at individual subfreezing treatments $(-3$, $-3.5,-4,-4.5$, and $-5{ }^{\circ} \mathrm{C}$ ) was on average $\approx 35 \%, 50 \%, 75 \%$, $32 \%$, and $38 \%$, respectively, higher than that of both the transgenic BB-CBF lines (Fig. 6B). These results indicated that transgenic BB- $C B F$-expressing $A$. thaliana plants had higher constitutive (i.e., under NA conditions) freezing tolerance than the WT plants.

After $6 \mathrm{~d}$ of cold acclimation, the $\mathrm{LT}_{50} \mathrm{~s}$ of WT, S3-7, and S3-11 plants were about $-7.32,-6.23$, and -6.37 , respectively (Fig. 6C, Table 2); consequently, the gain in FT during cold acclimation $\left(\Delta \mathrm{LT}_{50}=\mathrm{CA} F \mathrm{FT}-\mathrm{NA} F \mathrm{FT}\right)$ by these genotypes was $3.33,1.5$, and $1.59{ }^{\circ} \mathrm{C}$, respectively. The relative freeze-thaw

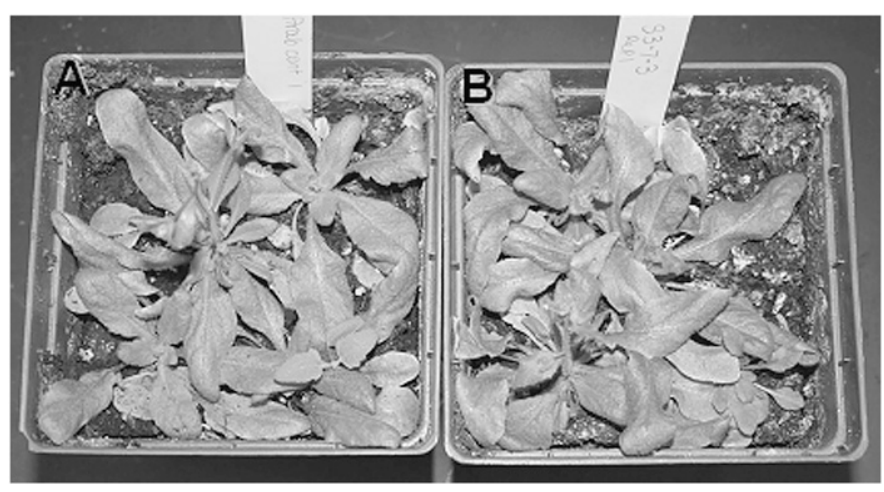

Fig. 5. Representative wild-type (A) and transgenic highbush blueberry C-repeat binding factor (BB-CBF) overexpressing (B) Arabidopsis thaliana plants.
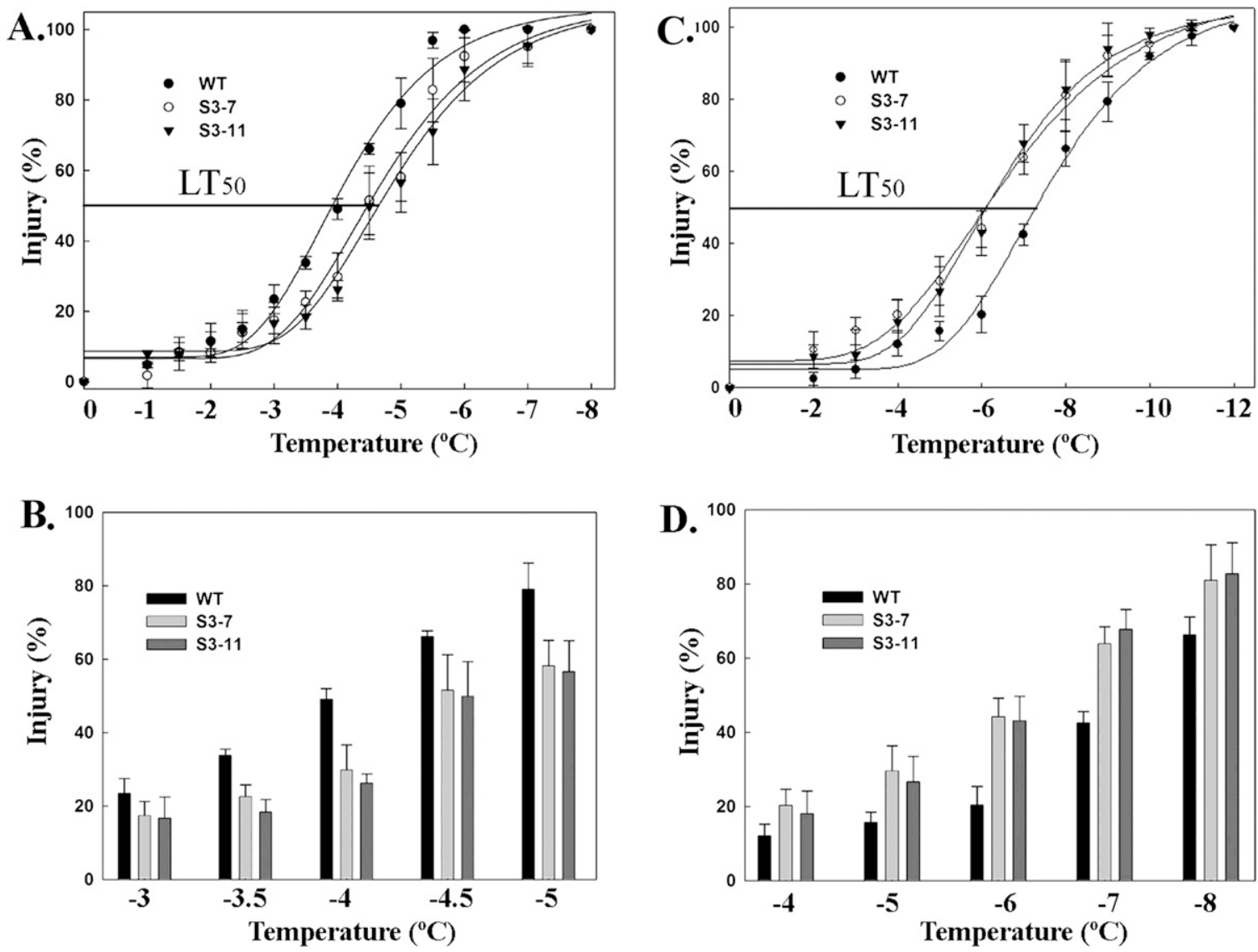

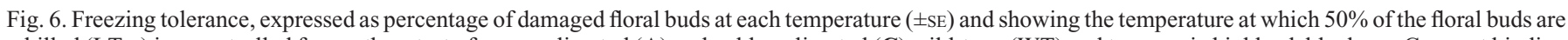
killed $\left(\mathrm{LT}_{50}\right)$ in a controlled freeze-thaw test of non-acclimated (A) and cold-acclimated (C) wild-type (WT) and transgenic highbush blueberry C-repeat binding factor (BB-CBF) overexpressing Arabidopsis thaliana seedlings (S3-7 and S-11). Freezing injury [derived from percentage of ion leakage according to Lim et al., (1998)] of non-acclimated (B) and cold-acclimated (D) WT and transgenic (BB-CBF) overexpressing $A$. thaliana seedlings (S3-7 and S-11). 
Table 2. Freezing tolerance of non-acclimated (NA) and coldacclimated (CA) wild-type (WT) and transgenic (BB-CBF overexpressing) Arabidopsis thaliana seedlings (lines S3-7 and S-11) as assessed by a laboratory freeze-thaw stress test. Data are expressed as the temperature at which $50 \%$ of the floral buds are killed $\left(\mathrm{LT}_{50}\right)$ in a controlled freeze-thaw test.

\begin{tabular}{lccc}
\hline & $\mathrm{WT}$ & $\mathrm{S} 3-7$ & $\mathrm{~S} 3-11$ \\
\cline { 2 - 4 } Treatment & \multicolumn{3}{c}{$\mathrm{LT}_{50}\left[\mathrm{mean} \pm \mathrm{SD}\left({ }^{\circ} \mathrm{C}\right)\right]$} \\
\hline NA & $-3.99 \pm 0.06^{\mathrm{z}}$ & $-4.73 \pm 0.38 \mathrm{a}$ & $-4.84 \pm 0.42 \mathrm{a}$ \\
CA & $-7.32 \pm 0.26$ & $-6.23 \pm 0.58 \mathrm{~b}$ & $-6.37 \pm 0.48 \mathrm{~b}$
\end{tabular}

${ }^{\mathrm{z}}$ Letters indicate significantly different versus WT as determined by Student's $t$ test at the following probability levels: a) $P<0.01$ and b) $P<0.05$. Where letters are not listed, the values are not significantly different from WT.

injury of CA BB- $C B F$ lines at various subfreezing temperatures $\left(-4,-5,-6,-7\right.$, and $\left.-8{ }^{\circ} \mathrm{C}\right)$ were on average $\approx 60 \%, 85 \%, 115 \%$, $55 \%$, and $25 \%$, respectively, greater than the freezing injury of corresponding WT controls (Fig. 6D). Differences in comparative injury response at NA and CA states for the BB-CBF lines and WT (as gleaned from results above) and their CAderived $\triangle \mathrm{LT}_{50}$ values indicate that $\mathrm{BB}-C B F$ lines had lower cold acclimation ability than the WT $A$. thaliana plants.

\section{Discussion}

The reverse subtracted library we created previously was enriched for transcripts that were expressed at higher levels in dormant 'Bluecrop' flower buds at 0 chill units (the end of September) than at 400 chill units (early December) (Naik et al., 2007). This library yielded fragments of a putative $C B F$ like gene. Higher expression of the blueberry $C B F$-like gene at 0 chill units than at 400 chill was confirmed with real-time PCR (discussed in greater detail in the following paragraph). Sequence analysis suggested that the $C B F / D R E B$ fragments might represent the 5' and 3' ends of the same $C B F$ gene. Therefore, we used the sequence data to design primers in an attempt to amplify the full coding sequence of the putative $C B F$ gene from genomic DNA of the highbush blueberry cultivar Bluecrop. We successfully amplified the coding region of the putative BB$C B F$ and confirmed identity by comparison of the deduced amino acid sequence to CBF/DREB proteins from other plants. From a PAUP* analysis, it was not surprising that the most closely related sequence currently in GenBank (accessed 25 Mar. 2009) is a lingonberry DREB1 mRNA sequence (accession no. FJ429388) because lingonberry and blueberry are in the same genus.

Expression of the BB- $C B F$ gene was also studied in floral buds throughout the dormant period in two blueberry cultivars with different freezing tolerances ('Bluecrop' and 'Tifblue', with maximum midwinter cold hardiness levels of about -27 and $-20{ }^{\circ} \mathrm{C}$, respectively). As expected, from the abundance of the $C B F$-like clones in the reverse subtracted library of 'Bluecrop' and because it is a transcription factor, expression was highest at the earliest time point ( 0 chill units) in late September. Expression declined dramatically by 67 chill units (20 Oct.), and was at a minimum by the 399 and 779 chill unit time points ( 8 Dec. and $2 \mathrm{Feb}$.), when bud hardiness levels are at a maximum (Dhanaraj et al., 2007; Muthalif and Rowland, 1994). Finding that BB- $C B F$ expression was at the highest level in late September indicates that conditions under which temperatures still remained above $7{ }^{\circ} \mathrm{C}$ (hence, the accumulation of 0 chill units) induced $C B F$ expression in blueberry. The BB- $C B F$ gene may have been induced by gradually declining temperatures and/or shortening photoperiods, by some critical temperature above $7{ }^{\circ} \mathrm{C}$, or by some other factor. $C B F$ genes have been shown to be induced by short photoperiods in barley (Hordeum vulgare) (Stockinger et al., 2007) and eucalyptus (Eucalyptus gunnii) (El Kayal et al., 2006). It is also possible that, in woody perennials, $C B F$ is induced in the first stage of cold acclimation by dehydrating conditions in dormant flower buds before exposure to cold. Wake and Fennell (2000) reported that water content decreases in grape (Vitis spp.) buds with short-day treatments and may be a necessary factor in dormancy induction. Indeed, several other clones from the reverse subtracted library encode proteins potentially related to drought stress and/or abscisic acid signaling (Naik et al., 2007). It is also interesting that $\mathrm{BB}-C B F$ expression levels increased slightly in 'Bluecrop' by the 1234 chill unit time point $(18$ Mar.). At this point, buds had begun to swell and to deacclimate (Dhanaraj et al., 2007). Generally, during this time period, plants are exposed to fluctuating temperatures and may lose hardiness, gain hardiness, and lose hardiness again. This may explain the slight rise in $\mathrm{BB}-C B F$ expression. The comparison between 'Bluecrop' and 'Tifblue' indicated that BB-CBF expression was higher in the more cold-hardy cultivar, almost 4-fold higher in 'Bluecrop' than in 'Tifblue', at the earliest time point.

Function of the putative BB-CBF gene was confirmed by induction of the A. thaliana COR6.6 and COR78 genes in transgenic plants overexpressing the BB- $C B F$ under noninducing (non-cold-treated) conditions. However, overexpression of the BB-CBF did not result in induction of all the $C O R$ genes tested, such as COR15A and COR414-TM1. CBF/DREB genes appear to preferentially activate downstream genes containing certain variations (e.g., ACCGACNA/G/C, ACCGACNT, and A/GCCGACNT) in the CRT/DRE promoter element (Sakuma et al., 2006). Dubouzet et al. (2003) reported that overexpression of $C B F / D R E B$ genes from rice (Oryza sativa) in A. thaliana resulted in induction of some but not all $C O R$ genes. In that case, it was determined that the rice $C B F /$ $D R E B$ gene product preferentially binds GCCGAC over ACCGAC in the CRT/DRE promoter element of the target genes. Likewise, the BB-CBF may bind certain promoter regions better than others, but this remains to be determined. It should be noted, however, that the two $C O R$ genes that were induced by the BB-CBF have identical CRT/DRE elements (i.e., ACCGACAT), while COR15A contains a different CRT/ DRE (GCCGACCT). The CRT/DRE for COR414-TM1 appears to be ACCGACAT (in the antisense direction), but considering that the product of this gene is targeted to the thylakoid membrane, it may be regulated differently than many of the other $C O R$ genes.

Function of the BB- $C B F$ was further confirmed by showing that the transgenic A. thaliana lines exhibit increased cold tolerance over WT under non-acclimating conditions. However, the cold-acclimated transgenic plants were, in fact, slightly less freezing tolerant than the WT plants. The simplest explanation for these results is that overexpression of the BB$C B F$ in cold-acclimated $A$. thaliana interferes with the endogenous cold acclimation process to some degree. This could be through such mechanisms as feedback regulation or competition for binding sites in some $C O R$ gene promoters. 
In conclusion, the ability of the isolated $\mathrm{BB}-C B \mathrm{~F}$ gene to turn on certain downstream $C O R$ genes and increase freezing tolerance in NA $A$. thaliana plants, its temporal expression pattern in floral buds, and the relationship of its expression level with cold hardiness level in cultivars with different freezing tolerances all suggest that it is a functional member of the $C B F$ / $D R E B$ gene family in blueberry.

\section{Literature Cited}

Altschul, S.F., W. Gish, W. Miller, E.W. Myers, and D.J. Lipman. 1990. Basic local alignment search tool. J. Mol. Biol. 215:403410.

An, G., P.R. Ebert, A. Mitra, and S.B. Ha. 1988. Binary vectors, p. A3 1-13. In: S.B. Gelvin and R.A. Schilperoort (eds.). Plant molecular biology manual. Kluwer Academic Publishers, Dordrecht, The Netherlands.

Arora, R., L.J. Rowland, E.L. Ogden, A.L. Dhanaraj, C.O. Marian, M.K. Ehlenfeldt, and B. Vinyard. 2004. Dehardening kinetics, bud development, and dehydrin metabolism in blueberry cultivars during deacclimation at constant, warm temperatures. J. Amer. Soc. Hort. Sci. 129:667-674.

Cline, W.O. 1995. Infection of cold-injured blueberry stems by Botryosphaeria dothidea. J. Small Fruit Viticult. 3:95-98.

Clough, S.J. and A.F. Bent. 1998. Floral dip: A simplified method for Agrobacterium-mediated transformation of Arabidopsis thaliana. Plant J. 16:735-743.

Dhanaraj, A.L., J.P. Slovin, and L.J. Rowland. 2004. Analysis of gene expression associated with cold acclimation in blueberry floral buds using expressed sequence tags. Plant Sci. 166:863-872.

Dhanaraj, A.L., N.W. Alkharouf, H.S. Beard, I.B. Chouikha, B.F. Matthews, H. Wei, R. Arora, and L.J. Rowland. 2007. Major differences observed in transcript profiles of blueberry during cold acclimation under field and cold room conditions. Planta 225:735751.

Dubouzet, J.G., Y. Sakuma, Y. Ito, M. Kasuga, E.G. Dubouzet, S. Miura, M. Seki, K. Shinozaki, and K. Yamaguchi-Shinozaki. 2003. OsDREB genes in rice, Oryza sativa L., encode transcription activators that function in drought-, high-salt- and cold-responsive gene expression. Plant J. 33:751-763.

El Kayal, W., M. Navarro, G. Marque, G. Keller, C. Marque, and C. Teulieres. 2006. Expression profile of CBF-like transcriptional factor genes from Eucalyptus in response to cold. J. Expt. Bot. 57:24552469 .

Fowler, S. and M.F. Thomashow. 2002. Arabidopsis transcriptome profiling indicates that multiple regulatory pathways are activated during cold acclimation in addition to the CBF cold response pathway. Plant Cell 14:1675-1690.

Gilmour, S.J., D.G. Zarka, E.J. Stockinger, M.P. Salazar, J.M Houghton, and M.F. Thomashow. 1998. Low temperature regulation of the Arabidopsis CBF family of AP2 transcriptional activators as an early step in cold-induced COR gene expression. Plant J. 16:433442.

Gilmour, S.J., A.M. Sebolt, M.P. Salazar, J.D. Everard, and M.F. Thomashow. 2000. Overexpression of the arabidopsis $C B F 3$ transcriptional activator mimics multiple biochemical changes associated with cold acclimation. Plant Physiol. 124:1854-1865.

Hildebrand, P.D. and P.G. Braun. 1991. Factors affecting infection of lowbush blueberry by ascospores of Monilinia vaccinii-corymbosi. Can. J. Plant Pathol. 13:232-240.

Jaglo, K.R., S. Kleff, K.L. Amundsen, X. Zhang, V. Haake, J.Z. Zhang, T. Deits, and M.F. Thomashow. 2001. Components of the arabidopsis C-repeat/dehydration-responsive element binding factor coldresponse pathway are conserved in Brassica napus and other plant species. Plant Physiol. 127:910-917.

Jaglo-Ottosen, K.R., S.J. Gilmour, D.G. Zarka, O. Schabenberger, and M.F. Thomashow. 1998. Arabidopsis CBF1 overexpression induces COR genes and enhances freezing tolerance. Science 280:104-106.
Koncz, C. and J. Shell. 1986. The promoter of $\mathrm{T}_{\mathrm{L}}$-DNA gene 5 controls the tissue-specific expression of chimaeric genes carried by a novel type of Agrobacterium binary vector. Mol. Gen. Genet. 204:383-396. Lim, C.C., R. Arora, and E.C. Townsend. 1998. Comparing Gompertz and Richards functions to estimate freezing injury in Rhododendron using electrolyte leakage. J. Amer. Soc. Hort. Sci. 123:246-252.

Liu, Q., M. Kasuga, Y. Sakuma, H. Abe, S. Miura, K. YamaguchiShinozaki, and K. Shinozaki. 1998. Two transcription factors, DREB1 and DREB2, with an EREBP/AP2 DNA binding domain separate two cellular signal transduction pathways in drought- and low-temperature-responsive gene expression, respectively, in arabidopsis. Plant Cell 10:1391-1406.

Metz, A.M., R.T. Timmer, and K.S. Browning. 1992. Sequences for two cDNAs encoding Arabidopsis thaliana eukaryotic protein synthesis initiation factor 4A. Gene 120:313-314.

Moore, J.N. 1993. The blueberry industry of North America. Acta Hort. 346:15-26.

Moretti, S., F. Armougom, I.M. Wallace, D.G. Higgins, C.V. Jongeneel, and C. Notredame. 2007. The M-Coffee web server: A meta-method for computing multiple sequence alignments by combining alternative alignment methods. Nucleic Acids Res. 35:W645-W648.

Murashige, T. and F. Skoog. 1962. A revised medium for rapid growth and bioassays with tobacco tissue cultures. Physiol. Plant. 15:473479.

Muthalif, M.M. and L.J. Rowland. 1994. Identification of dehydrinlike proteins responsive to chilling in floral buds of blueberry (Vaccinium, section Cyanococcus). Plant Physiol. 104:1439-1447.

Naik, D., A.L. Dhanaraj, R. Arora, and L.J. Rowland. 2007. Identification of cold-responsive genes in blueberry (Vaccinium corymbosum L.) using a hybridization approach. Plant Sci. 173:213-222.

Peng, Y., W. Lin, W. Cai, and R. Arora. 2007. Overexpression of a Panax ginseng tonoplast aquaporin alters salt tolerance, drought tolerance and cold acclimation ability in transgenic arabidopsis plants. Planta 226:729-740.

Rowland, L.J., A.L. Dhanaraj, J.J. Polashock, and R. Arora. 2003. Utility of blueberry-derived EST-PCR primers in related Ericaceae species. HortScience 38:1428-1432.

Rowland, L.J., E.L. Ogden, M.K. Ehlenfeldt, and B. Vinyard. 2005. Cold hardiness, deacclimation kinetics, and bud development among 12 diverse blueberry genotypes under field conditions. J. Amer. Soc. Hort. Sci. 130:508-514.

Rozen, S. and H. Skaletsky. 2000. Primer3 on the WWW for general users and for biologist programmers, p. 365-386. In: S. Krawetz and S. Misener (eds.). Bioinformatics methods and protocols. Humana Press, Totowa, NJ.

Sakuma, Y., K. Maruyama, Y. Osakabe, F. Qin, M. Seki, K. Shinozaki, and K. Yamaguchi-Shinozaki. 2006. Functional analysis of an Arabidopsis transcription factor, DREB2A, involved in droughtresponsive gene expression. Plant Cell 18:1292-1309.

Sambrook, J., E.F. Fritsch, and T. Maniatis. 1989. Molecular cloning: A laboratory manual. 2nd ed. Cold Spring Harbor Laboratory Press, Cold Spring Harbor, NY.

Seki, M., M. Narusaka, H. Abe, M. Kasuga, K. Yamaguchi-Shinozaki, P. Carninci, Y. Hayashizaki, and K. Shinozaki. 2001. Monitoring the expression pattern of 1300 arabidopsis genes under drought and cold stresses by using a full-length cDNA microarray. Plant Cell 13:6172.

Shinozaki, K. and K. Yamaguchi-Shinozaki. 1996. Molecular responses to drought and cold stress. Curr. Opin. Biotechnol. 7:161-167.

Shinwari, Z.K., K. Nakashima, S. Miura, M. Kasuga, M. Seki, K. Yamaguchi-Shinozaki, and K. Shinozaki. 1998. An Arabidopsis gene family encoding DRE/CRT binding proteins involved in lowtemperature-responsive gene expression. Biochem. Biophys. Res. Commun. 250:161-170.

Stockinger, E.J., J.S. Skinner, K.P. Gardner, E. Francia, and N. Pecchioni. 2007. Expression levels of barley $C b f$ genes at the Frost resistance-H2 locus are dependent upon alleles at $\mathrm{Fr}-\mathrm{H} 1$ and $\mathrm{Fr}-\mathrm{H} 2$. Plant J. 51:308-321. 
Stockinger, E.J., S.J. Gilmour, and M.F. Thomashow. 1997. Arabidopsis thaliana $C B F 1$ encodes an AP2 domain-containing transcriptional activator that binds to the $\mathrm{C}$-repeat/DRE, a cis-acting DNA regulatory element that stimulates transcription in response to low temperature and water deficit. Proc. Natl. Acad. Sci. USA 94:1035-1040.

Swofford, D.L. 2000. PAUP*: Phylogenetic analysis using parsimony (*and other methods). Sinauer Associates, Sunderland, MA.

Thomashow, M.F. 1999. Plant cold acclimation: Freezing tolerance genes and regulatory mechanisms. Annu. Rev. Plant Physiol. Plant Mol. Biol. 50:571-599.

Timmermans, M.C.P., P. Maliga, J. Vieira, and J. Messing. 1990. The pFF plasmids: Cassettes utilising CaMV sequences for expression of foreign genes in plants. J. Biotechnol. 14:333-344.
Wake, C.M.F. and A. Fennell. 2000. Morphological, physiological and dormancy responses of three Vitis genotypes to short photoperiod. Physiol. Plant. 109:203-210.

Wang, H., R. Datla, F. Georges, M. Loewen, and A.J. Cutler. 1995. Promoters from kin1 and cor6.6, two homologous Arabidopsis thaliana genes: Transcriptional regulation and gene expression induced by low temperature, ABA, osmoticum and dehydration. Plant Mol. Biol. 28:605-617.

Weiser, C.J. 1970. Cold resistance and injury in woody plants. Science 169:1269-1278.

Wilkins, T.A. and L.B. Smart. 1996. Isolation of RNA in plant tissues, p. 21-41. In: P.A. Krieg (ed.). A laboratory guide to RNA isolation, analysis and synthesis. Wiley, New York. 